\title{
Relationship and Predictive Role of the Dual Expression of FGFR and IL-8 in Metastatic Renal Cell Carcinoma Treated with Targeted Agents
}

\author{
ROBERTO IACOVELLI ${ }^{1}$, MICHELE DE TURSI ${ }^{2}$, CLAUDIA MOSILLO $^{3}$, ANTONIO CIARDI ${ }^{4}$, \\ CONSIGLIA CARELLA ${ }^{2}$, CLARA NATOLI $^{2}$, GIUSEPPE NASO $^{3}$ and ENRICO CORTESI ${ }^{3}$ \\ ${ }^{1}$ Department of Medicine, Medical Oncology Unit, Azienda Ospedaliera Universitaria Integrata Verona, Verona, Italy; \\ ${ }^{2}$ Department of Oral and Medical Sciences, Oncology Unit, G. D’Annunzio University, Chieti, Italy; \\ ${ }^{3}$ Department of Radiology, Oncology and Human Pathology, \\ Oncology Unit, Sapienza University of Rome, Rome, Italy; \\ ${ }^{4}$ Department of Radiology, Oncology and Human Pathology, \\ Human Pathology Unit, Sapienza University of Rome, Rome, Italy
}

\begin{abstract}
Background/Aim: The expression of $I L-8$ and FGFR has been related to prognosis and pathological features in renal cell carcinoma. We investigated the relationship between $I L-8$ and FGFR and the outcome in metastatic renal cell carcinoma $(m R C C)$ patients. Materials and Methods: Clinical data and histological samples of patients affected by $\mathrm{mRCC}$ and treated with targeted agents were reviewed. The expression of proteins was assessed using immunohistochemistry. Results: FGFR1, FGFR2, and $I L-8$ were found to be expressed in 16\%, 30\%, and 50\% of cases, respectively. Significant correlations were found between selected proteins. A lack of expression of FGFR2 and IL8 was found to be correlated with increased progression-free survival (PFS). The survival rate at 24 months was 44\%, 38\%, and 79\% of those expressing both, one, or none of the evaluated proteins, respectively $(p=0.047)$. Conclusion: This analysis found a relationship between the expression of IL-8 and FGFR2 in mRCC patients treated with targeted agents.
\end{abstract}

Renal cell carcinoma (RCC) is the sixth most common cancer in men and the eighth in women in the United States, with an estimated 65,150 new cases and 13,680 deaths expected to occur this year (1). In Europe, the incidence and

Correspondence to: Roberto Iacovelli, Azienda Ospedaliera Universitaria Integrata di Verona, Medical Oncology Unit, Piazzale L.A., Scuro 10, 37134 Verona, Italy. Tel: +39 045812115, e-mail: roberto.iacovelli@aovr.veneto.it

Key Words: FGFR, IL-8, mRCC, progression-free survival, predictive factor. mortality of RCC are estimated to be 71,739 and 31,293 cases per year, respectively $(2,3)$.

Since vascular endothelial growth factor (VEGF), its tyrosine kinase receptor (VEGFR), and the mammalian target of rapamycin (mTOR) serine threonine kinase have been commonly used as targets for therapies, the survival rate of metastatic RCC (mRCC) patients has been notably improved (4). Nevertheless, $20 \%$ of patients progress during first-line treatment and are considered primary refractory. Based on this evidence, the identification of predictive factors remains an unmet need for the clinical management of advanced disease, while available classifications based on clinical parameters have only a prognostic role (5).

Interleukin-8 (IL-8), alternatively known as CXCL8, is a pro-inflammatory CXC chemokine whose expression has been shown to be regulated by a number of different stimuli, including inflammatory signals, chemical and environmental stresses, and steroid hormones (6). Similarly, fibroblast growth factor receptors (FGFRs) have been reported to have a specific role in cell proliferation and migration, differentiation, apoptosis, survival, epithelial-mesenchymal transition, and tumorigenesis (7). These factors belong to a family of four tyrosine kinase receptors and can be activated by their cognate ligands and by cell adhesion molecules such as the neural cell adhesion molecule (NCAM) (7). Both IL-8 and FGFR have been reported to have a prognostic role in $\operatorname{RCC}(8,9)$, but their relationship has never been investigated.

In the present study, we aimed to investigate the correlation between the expression of IL-8 and FGFR and the predictive role of their combined expression in metastatic RCC (mRCC) patients treated with targeted agents. 


\section{Patients and Methods}

Patients. We identified, at two University Centers in Italy, all the patients treated with targeted agents for metastatic disease who had previously received radical nephrectomy or nephron-sparing surgery or had undergone a tumor biopsy. All the selected patients were required to have in their patient file histological samples from their primary tumors or metastatic sites and adequate clinical information and follow-up details. All patients gave their written informed consent and the study received the approval of the Institutional Review Board and Ethical Committee.

Immunohistochemical staining. Tumor samples were obtained from formalin-fixed and paraffin-embedded surgical specimens. After deparaffinization, rehydration, and the blocking of endogenous peroxidase activity, immunohistochemical staining was performed using a polyclonal rabbit anti-IL-8 antibody (sc-7922, Santa Cruz Biotechnology, CA, USA) at a 1:50 dilution, a polyclonal rabbit anti-FGFR1 antibody (Flg; Santa Cruz Biotechnology) at a 1:200 dilution, a polyclonal rabbit anti-FGFR2 antibody (Bek, Santa Cruz Biotechnology) at a 1:200 dilution; a secondary antibody; and a chromogenic substrate (ChromoMap DAB, 760-159 Ventana, Arizona, USA). The microscopic slides from all the specimens were reviewed by a urologic pathologist (A.C.) without prior knowledge of patient outcomes. The percentages of tumor cells that stained positive for FGFR1, FGFR2, and IL-8 were quantified. Both the cytoplasmic and membranous staining were scored as 0 (negative), 1 (weakly positive), and 2 (strongly positive). In addition, all cases with a $<5 \%$ expression of the marker were considered to be negative.

Statistical methods. Comparisons of the pathologic and clinical features and marker expression were evaluated using the Chi2 test, T-test, and Wilcoxon test when appropriate. Correlations among the qualitative variables were evaluated by a Spearman test $\left(r_{s}\right)$. Survival was estimated using the Kaplan-Meier method. The rates of patients without disease progression at 12 months that were also alive at 24 months were estimated. The duration of the follow-up was calculated from the date of first-line treatment to the date of death or the last follow-up.

All the statistical analyses were conducted using PASW (Predictive Analytics SoftWare) (v 21; IBM SPSS), with a 2-sided $p<0.05$ considered to be statistically significant.

\section{Results}

Overall population. Overall, 36 patients were included in the final analysis. Sunitinib was the most commonly used firstline therapy. The main baseline characteristics of the patients are reported in Table I. The majority of patients were male, and the median age was 60 years. $42 \%$ of them had metastatic disease at diagnosis, 94\% underwent a radical nephrectomy, and $92 \%$ had clear cell histology. Based on Memorial Sloan Kettering Cancer Center (MSKCC) prognostic classification, this was good in $30 \%$ of cases, intermediate in $56 \%$, and poor in $14 \%$. The median time from diagnosis to the start of therapy was 10.1 months (IQR=1.6-28.0).
Table I. Main characteristics of patients.

\begin{tabular}{ll}
\hline Characteristics & $\begin{array}{c}\text { Patients } \\
\mathrm{N}=36\end{array}$ \\
\hline Male & $64 \%$ \\
Median age (IQR) & $60(52.1-65.8)$ \\
Histology & $92 \%$ \\
Clear cells & $8 \%$ \\
Non -clear cells & $94 \%$ \\
Nephrectomy & $42 \%$ \\
Metastatic t diagnosis & $47 \%$ \\
Hb<LLN & $17 \%$ \\
LDH>ULN & $14 \%$ \\
Karnofsky PS $<80 \%$ & \\
Metastatic sites $\geq 2$ & \\
Prognostic MSKCC group & $30 \%$ \\
Good & $56 \%$ \\
Intermediate & $14 \%$ \\
Poor & \\
First-line therapy & $75 \%$ \\
Sunitinib & $8 \%$ \\
Pazopanib & $6 \%$ \\
Sorafenib & $6 \%$ \\
Bevacizumab & $5 \%$ \\
Temsirolimus & \\
\hline
\end{tabular}

At the cut-off date, 30 patients had disease progression and 25 were deceased. The median follow-up was 54.4 months, the median survival 33.0 months $(95 \% \mathrm{CI}=12.0$ 54.0), and the median PFS at the time of first-line treatment 11.8 months $(95 \% \mathrm{CI}=7.7-16.0)$. Finally, $28 \%$ of patients had PFS shorter than six months

$I L-8$. The expression of IL- 8 was found to be negative (IL$8-)$ in 18 patients $(50 \%)$ and positive (IL-8+) in the remaining 18 cases. Among these, the staining was considered to be $1+$ in five $(14 \%)$ and $2+$ in $13(36 \%)$ cases (Figure 1). No significant differences were found among the baseline characteristics of patients and the positive or negative expression of IL-8.

The rate of patients without disease progression at 12 months was $66 \%$ in the IL- 8 - subjects and $25 \%$ in the IL-8+ cases $(p=0.022)$. The rate of patients alive at 24 months was $78 \%$ in the IL-8- group and $33 \%$ in those who were IL-8+ $(p=0.009)$ (Figure 2).

FGFR1. The expression of FGFR1 was found to be negative (FGFR1-) in 30 cases (84\%), and positive (FGFR1+) in the remaining six. Among these, the staining was considered to be $1+$ in three cases $(8 \%)$ and $2+$ in the remaining three $(8 \%)$ (Figure 1). No significant differences were found among the baseline characteristics of the patients and the positive or negative expression of FGFR1. 

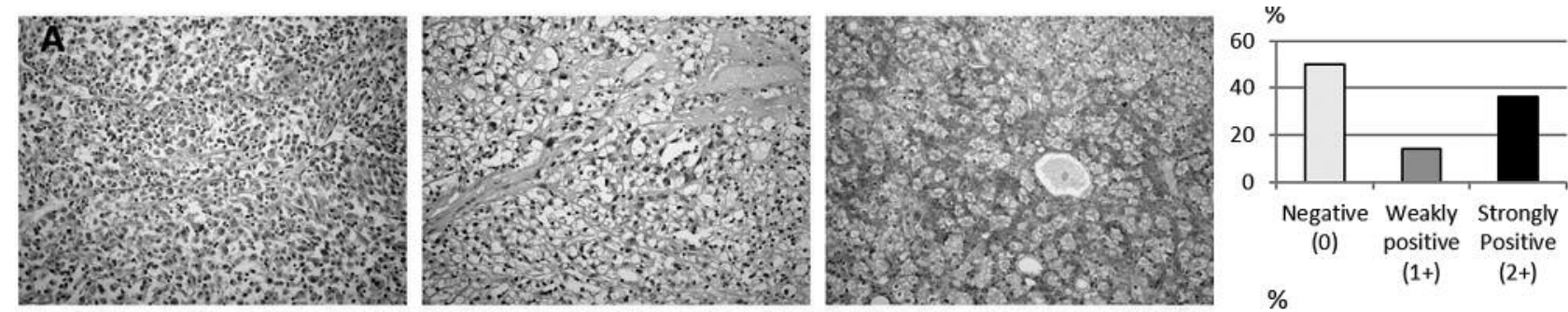

(0) positive Positive
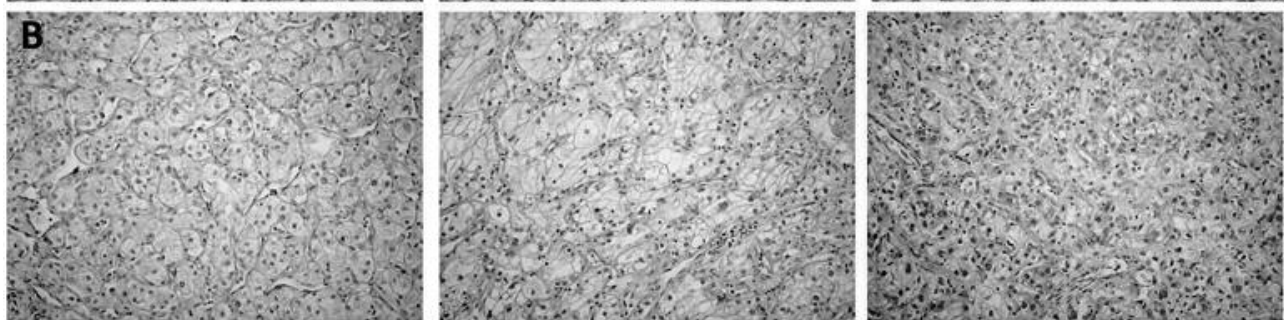

$(1+$

$(2+)$
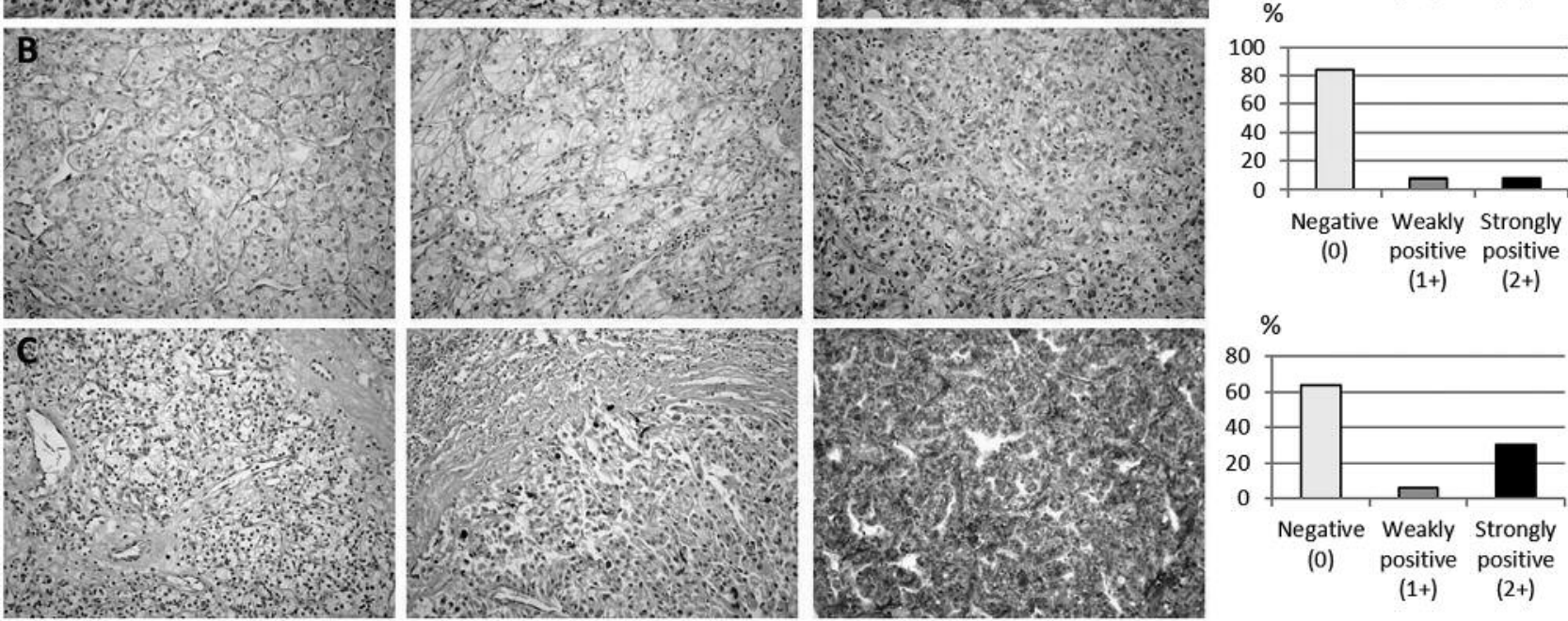

Negative Weakly Strongly

(0) positive positive

$(1+) \quad(2+)$

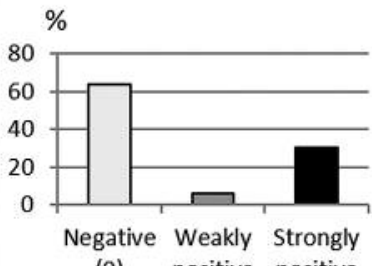

(0) positive positive

$(1+) \quad(2+)$

Figure 1. Expression and staining score (\%) for IL-8 (A), FGFR1 (B) and FGFR2 (C).

A

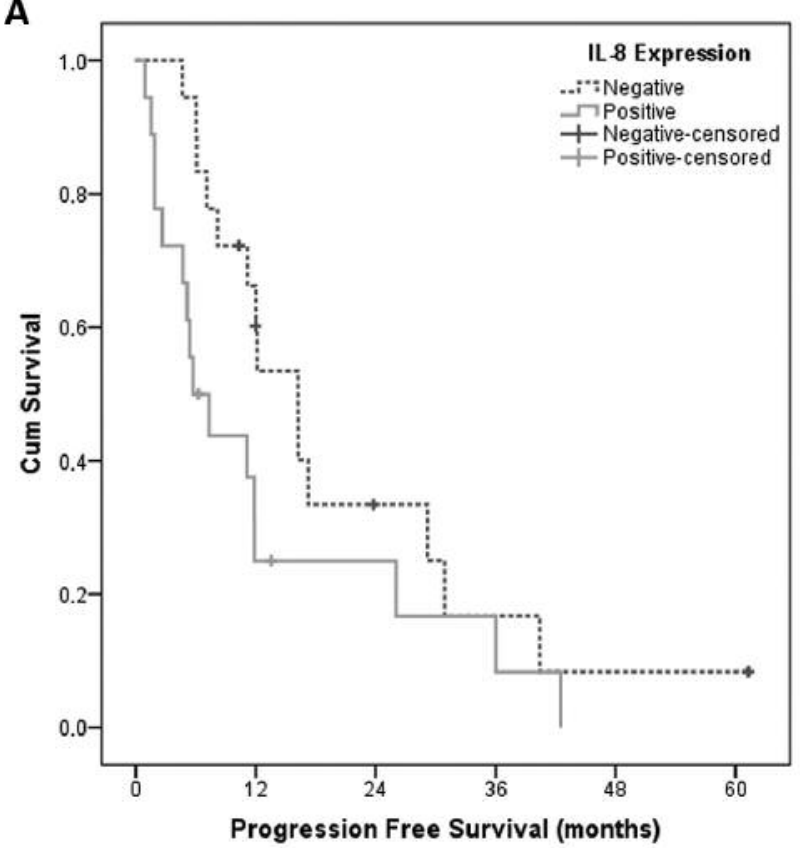

B

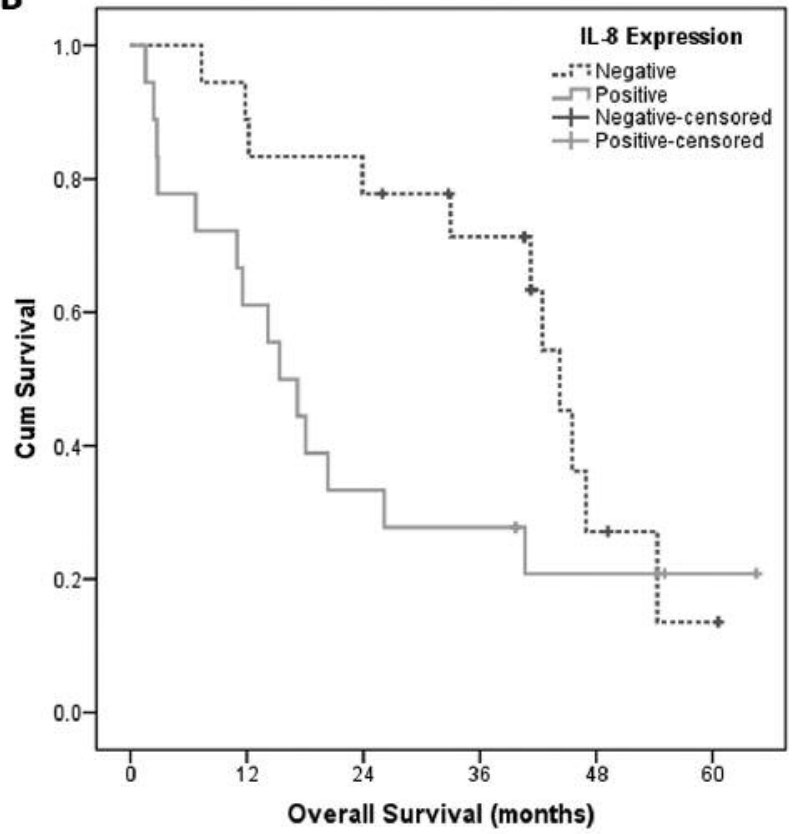

Figure 2. Progression-free survival (A) and overall survival (B) based on the expression of IL-8. 
A

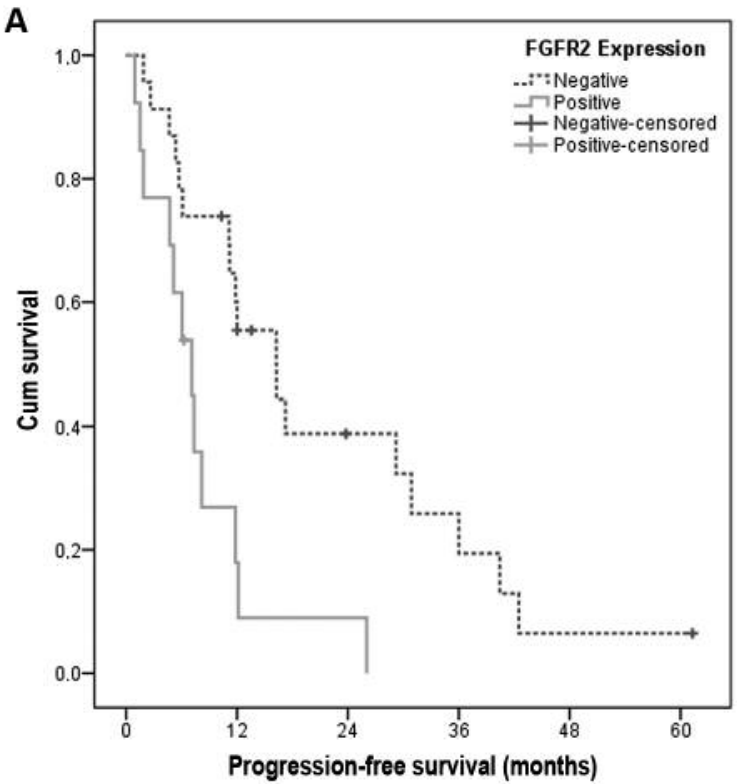

B

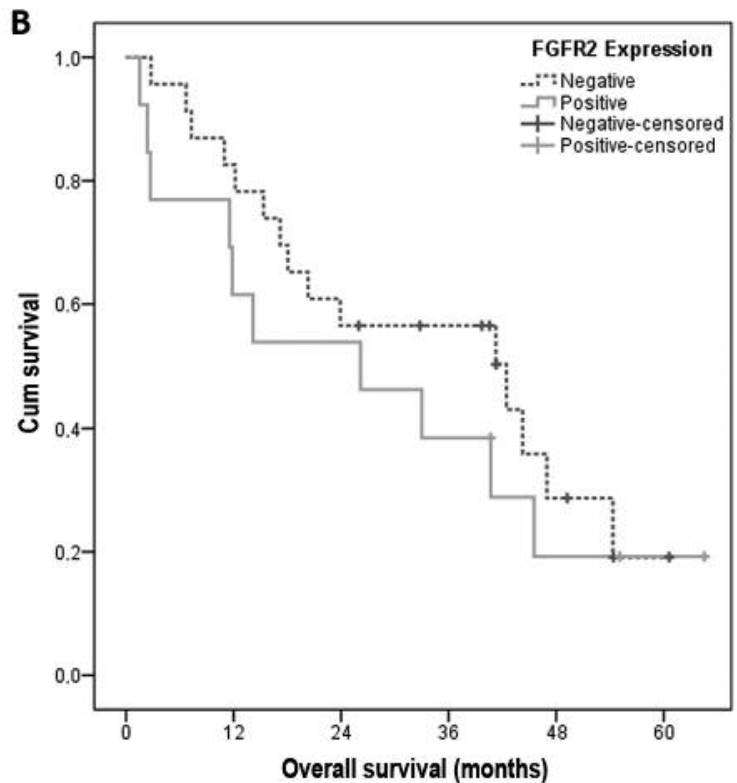

Figure 3. Progression-free survival (A) and overall survival (B) based on expression of FGFR2.

A

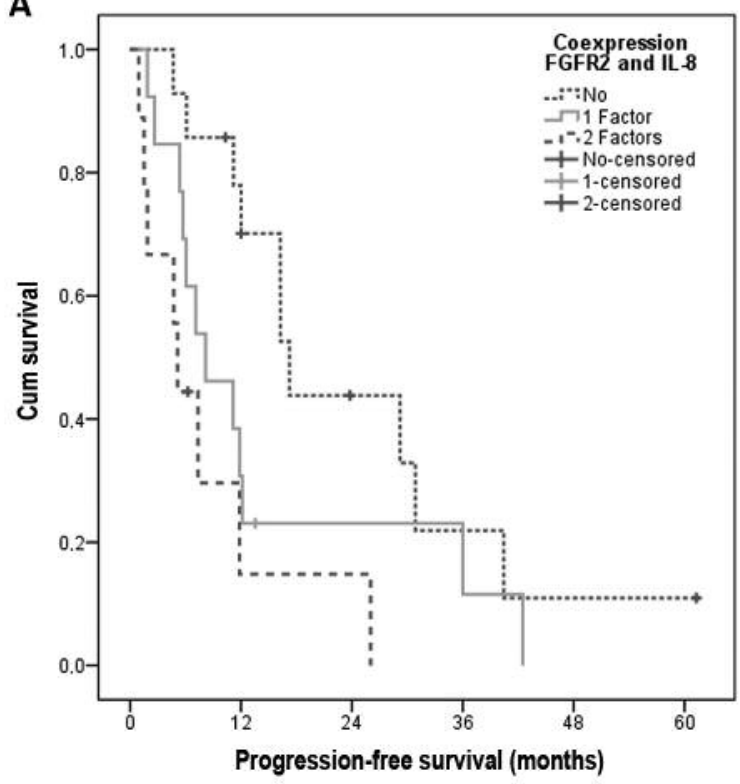

B

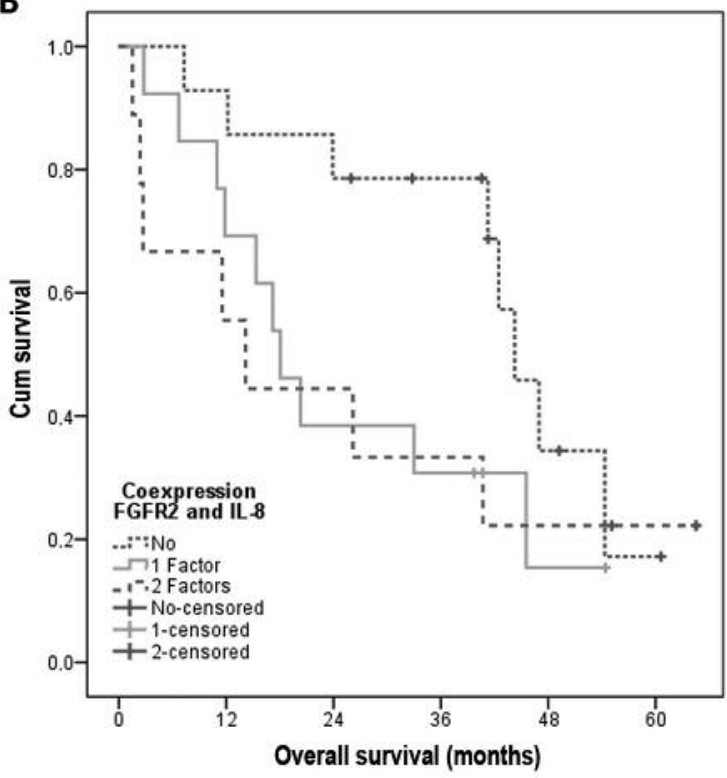

Figure 4. Progression-free survival (A) and overall survival (B) based on co-expression of FGFR2 and IL-8.

The rate of cases without progression at 12 months was $46 \%$ in both the FGFR1- and FGFR1+ patients. The rate of patients alive at 24 months was $53 \%$ in the FGFR1- cases and $67 \%$ in the FGFR $1+$ subjects $(p=0.8)$.
FGFR2. The expression of FGFR2 was found to be negative (FGFR2-) in 23 cases (64\%) and positive (FGFR2+) in the remaining 13 . Among these, the staining was $1+$ in two $(6 \%)$ and $2+$ in $11(30 \%)$ cases (Figure 1). No significant 
differences were found among the baseline characteristics of the patients and the positive or negative expression of FGFR2.

The rate of patients without disease progression at 12 months was $60 \%$ in the FGFR2- patients and $18 \%$ in those who were FGFR2+ $(p=0.015)$. The rate of patients alive at 24 months was $57 \%$ in the FGFR2- and 54\% in the FGFR2+ patients $(p=0.3)$ (Figure 3$)$.

Correlations. Among the $18 \mathrm{IL}-8+$ patients, five were also FGFR1+ and nine were FGFR2+. Among the 18 IL-8- cases, only one patient was FGFR1+ and four were FGFR2+. Significant correlations were found between IL-8 and FGFR 1 $\left(\mathrm{r}_{\mathrm{s}}=0.30\right.$; one-tail $\left.p=0.039\right)$, IL-8 and FGFR2 $\left(\mathrm{r}_{\mathrm{s}}=0.29 ;\right.$ one-tail $\left.p=0.044\right)$, and FGFR1 and FGFR2 $\left(\mathrm{r}_{\mathrm{s}}=0.44\right.$; one-tail $\left.p=0.004\right)$.

In order to investigate the predictive role of IL-8 and FGFR2, we analyzed the impact of their combined expression on survival. The rate of patients without disease progression at 12 months was $16 \%, 31 \%$, and $78 \%$ in those who expressed both, one, or none of the evaluated factors, respectively $(p=0.012)$. The rate of patients alive at 24 months was $44 \%, 38 \%$, and $79 \%$ in patients who expressed both, one, or none of the evaluated proteins, respectively $(p=0.047)$ (Figure 4). A significant correlation was found between PFS, that was shorter than six months, and the dual expression of FGFR2 and IL- $8\left(\mathrm{r}_{\mathrm{s}}=0.42\right.$; one-tail $\left.p=0.005\right)$.

\section{Discussion}

This analysis reports the predictive role of the dual expression of IL- 8 and FGFR2 in mRCC patients treated with targeted therapies. The expression of these two proteins is related to a shorter PFS under treatment with targeted agents as well as with a trend for shorter overall survival. As these proteins have been evaluated on tumor tissue from the primitive tumor, their expression might be related to an innate resistance to anti-angiogenic agents.

FGFR2 has been previously related to resistance to antiangiogenic therapies in an RCC experimental model (10). Welti and colleagues reported that FGF2 is a potent mediator of endothelial cell resistance to sunitinib (10). They demonstrated that FGF2 suppresses sunitinib anti-angiogenic activity by the direct stimulation of pro-angiogenic signaling in endothelial cells. Moreover, they showed that sunitinib is able to inhibit the VEGF-mediated activation of ERK1/2 and PLC $\gamma$, but not the FGF2-mediated activation of ERK1/2 and PLC $\gamma$ (10). The same authors confirmed the expression of FGF2 in both tumor and endothelial cells, suggesting that FGF2 can potently suppress the anti-angiogenic activity of sunitinib.

In the present study, we report that about $30 \%$ of our RCC patients who constitutively expressed FGFR2 and had an intrinsic resistance to sunitinib and had a shorter PFS, compared to those with a negative or lower expression of this protein.

Consistently, Huang et al., reported that the 786-O clearcell RCC (ccRCC) cell line expressing high levels of IL-8 was resistant to sunitinib (11). Moreover, they found a higher plasma level of IL-8 in mice with RCC tumors resistant to sunitinib. The direct relationship between IL-8 and resistance to sunitinib was also confirmed by the use of a monoclonal antibody against IL-8 that reversed this resistance (11). Similarly, in our study, we were able to confirm that high IL8 immunohistochemical expression in human RCC is correlated to the refractoriness to sunitinib (11).

IL-8 seems to have an interesting modulatory effect on the response to targeted agents, and two studies have also investigated $I L-8$ gene polymorphisms in 397 patients treated with sunitinib or pazopanib for mRCC (12). It was reported that the first patients enrolled in the phase II and phase III pazopanib trials with the 2767TT variant had an inferior PFS compared with the wild-type AA genotype, with a median PFS of 27 and 48 weeks, respectively $(\mathrm{HR}=1.8 ; 95 \% \mathrm{CI}=1.2-$ $2.7 ; p=0.009)$. Similarly, those with the IL-8-251AA genotype had inferior median PFS compared to their counterparts with the wild-type TT genotype (32 vs. 49 weeks; $\mathrm{HR}=1.7 ; 95 \% \mathrm{CI}=1.1-2.5 ; p=0.01)$. Nevertheless, no significant relationship was found between the IL-8 genotypes and the response rate to therapy (12). The second study analyzed 27 single nuclear polymorphisms (SNPs) within 13 genes using data from mRCC patients treated with pazopanib in a clinical study and the variants related to the outcome have been tested in a larger group of mRCC patients treated with sunitinib or pazopanib. Two IL-8 SNPs were associated with overall survival (OS) (rs1126647 and rs4073) and were found to be strongly correlated with each other. Finally, the rs 1126647 genotype was validated using two datasets and confirmed as an independent prognostic variant (13).

Although both FGFR and IL-8 have a prognostic role in RCC and both are related to angiogenesis and tumor progression, their combined role has been never investigated in this tumor type. A similar correlation was tested by Giri and Ittman in tissues from patients affected by prostatic hyperplasia (14). They found that IL-8 produced by prostatic epithelial cells can induce FGF2, promoting abnormal proliferation of the prostatic transition zone that is a critical event in the pathogenesis of benign prostatic hyperplasia (14). In experimental models, it was proved that the use of recombinant IL-8 increased by threefold FGF2 release from prostatic stromal cells, inducing increased levels of FGF2 mRNA. This relationship has also been proven in human prostate tissue in vivo (14).

Our study confirms the negative predictive role of the dual expression of FGF2 and IL-8 in RCC. Main limitations of 
the study are its retrospective nature, the low number of included cases, and the interval of time from the initial diagnosis and the start of therapy, that may affect the expression of the investigated proteins. If validated, these data may improve the selection of mRCC patients, and suggest possible targets for treatment.

FGFR inhibitors have already been tested in unselected mRCC in at least two large trials. In the GOLD phase III study, patients previously treated with VEGFR and mTOR inhibitors were randomized to receive the dual VEGFR and FGFR inhibitor dovitinib or the standard care of sorafenib, with a similar outcome reported for both therapies (15). More recently, another VEGFR/FGFR inhibitor, lenvatinib, was tested in patients previously treated with VEGFR inhibitors. Patients were randomized to receive either lenvatinib plus everolimus, single-agent lenvatinib, or singleagent everolimus, with a significantly longer PFS reported in patients treated with lenvatinib plus everolimus compared to everolimus alone (16). These experiences suggest a way forward for the use of the FGFR inhibitor in $\mathrm{mRCC}$, but also highlight the importance of patient selection.

Finally, our study may pave the way for further analyses in order to improve knowledge on prognostic factors and the selection of patients in future clinical trials.

\section{Conflicts of Interest}

The Authors declare no conflicts of interest.

\section{Acknowledgements}

The "Fondazione Luigi e Gabriella D'Amato Onlus" for the support in the cancer research. Novartis Farma Italy for support in the consumable materials.

\section{References}

1 American Cancer Society Cancer Facts \& Figures 2013. American Cancer Society, Atlanta, USA.

2 Ferlay J, Steliarova-Foucher E, Lortet-Tieulent J, Rosso S, Coebergh JW, Comber H, Forman D and Bray F: Cancer incidence and mortality patterns in Europe: estimates for 40 countries in 2012. Eur J Cancer 49: 1374-1403, 2013.

3 Bray F, Ren JS, Masuyer E and Ferlay J: Estimates of global cancer prevalence for 27 sites in the adult population in 2008 . Int J Cancer 132: 1133-1145, 2013.

4 Iacovelli R, Sternberg CN, Porta C, Verzoni E, Braud F, Escudier $\mathrm{B}$ and Procopio G: Inhibition of the VEGF/VEGFR pathway improves survival in advanced kidney cancer: A systematic review and meta-analysis. Curr Drug Targets 16: 164-170, 2015.

5 Procopio G, Verzoni E, Iacovelli R, Biasoni D, Testa I, Porcu L and De Braud F: Prognostic factors for survival in patients with metastatic renal cell carcinoma treated with targeted therapies. Br J Cancer 107: 1227-1232, 2012.

6 Waugh DJ and Wilson C: The interleukin-8 pathway in cancer. Clin Cancer Res 14: 6735-6741, 2008.
7 Touat M, Ileana E, Postel-Vinay S, André F and Soria JC: Targeting FGFR signaling in cancer. Clin Cancer Res 21: 26842694, 2015.

8 Sanmamed MF, Carranza-Rua O, Alfaro C, Oñate C, MartínAlgarra S, Perez G, Landazuri SF, Gonzalez A, Gross S, Rodriguez I, Muñoz-Calleja C, Rodríguez-Ruiz M, Sangro B, López-Picazo JM, Rizzo M, Mazzolini G, Pascual JI, Andueza MP, Perez-Gracia JL and Melero I: Serum interleukin- 8 reflects tumor burden and treatment response across malignancies of multiple tissue origins. Clin Cancer Res 20: 5697-5707, 2014.

9 Nanus DM, Schmitz-Dräger BJ, Motzer RJ, Lee AC, Vlamis V, Cordon-Cardo C, Albino AP and Reuter VE: Expression of basic fibroblast growth factor in primary human renal tumors: correlation with poor survival. J Natl Cancer Inst 85: 1597-1599, 1993.

10 Welti JC, Gourlaouen M, Powles T, Kudahetti SC, Wilson P, Berney DM and Reynolds AR: Fibroblast growth factor 2 regulates endothelial cell sensitivity to sunitinib. Oncogene 30 : 1183-1193, 2011.

11 Huang D, Ding Y, Zhou M, Rini BI, Petillo D, Qian CN, Kahnoski R, Futreal PA, Furge KA and Teh BT: Interleukin-8 mediates resistance to antiangiogenic agent sunitinib in renal cell carcinoma. Cancer Res 70: 1063-1071, 2010.

$12 \mathrm{Xu}$ CF, Bing NX, Ball HA, Rajagopalan D, Sternberg CN, Hutson TE, de Souza P, Xue ZG, McCann L, King KS, Ragone LJ, Whittaker JC, Spraggs CF, Cardon LR, Mooser VE and Pandite LN: Pazopanib efficacy in renal cell carcinoma: evidence for predictive genetic markers in angiogenesis-related and exposure-related genes. J Clin Oncol 29: 2557-2564, 2011.

$13 \mathrm{Xu}$ CF, Johnson T, Garcia-Donas J, Choueiri TK, Sternberg CN, Davis ID, Bing N, Deen KC, Xue Z, McCann L, Esteban E, Whittaker JC, Spraggs CF, Rodríguez-Antona C, Pandite LN and Motzer RJ : IL8 polymorphisms and overall survival in pazopanib- or sunitinib-treated patients with renal cell carcinoma. Br J Cancer 112: 1190-1198, 2015.

14 Giri D and Ittmann M: Interleukin-8 is a paracrine inducer of fibroblast growth factor 2, a stromal and epithelial growth factor in benign prostatic hyperplasia. Am J Pathol 159: 139-147, 2001.

15 Motzer RJ, Porta C, Vogelzang NJ, Sternberg CN, Szczylik C, Zolnierek J, Kollmannsberger C, Rha SY, Bjarnason GA, Melichar B, De Giorgi U, Grünwald V, Davis ID, Lee JL, Esteban E, Urbanowitz G, Cai C, Squires M, Marker M, Shi $\mathrm{MM}$ and Escudier B: Dovitinib versus sorafenib for third-line targeted treatment of patients with metastatic renal cell carcinoma: an open-label, randomised phase 3 trial. Lancet Oncol 15: 286-296, 2014.

16 Motzer RJ, Hutson TE, Glen H, Michaelson MD, Molina A, Eisen T, Jassem J, Zolnierek J, Maroto JP, Mellado B, Melichar B, Tomasek J, Kremer A, Kim HJ, Wood K, Dutcus C and Larkin J: Lenvatinib, everolimus, and the combination in patients with metastatic renal cell carcinoma: A randomised, phase 2, open-label, multicentre trial. Lancet Oncol 16: 14731482, 2015. 